Jurnal Basicedu Volume 2 Nomor 1 April 2020 Halaman 23- 27

EDUKATIF: JURNAL ILMU PENDIDIKAN

Research \& Learning in Education

https://edukatif.org/index.php/edukatif/index

\title{
PENTINGNYA MEDIA DALAM PEMBELAJARAN GUNA MENINGKATKAN HASIL BELAJAR DI SEKOLAH DASAR
}

\author{
Rizki Wahyuningtyas ${ }^{1}$, Bambang Suteng Sulasmono \\ Universitas Kristen Satya Wacana, Jawa Tengah, Indonesia ${ }^{12}$ \\ e-mail : rizkiw547@gmail.com ${ }^{1}$, sulasmonobambang@yahoo.com ${ }^{2}$
}

\begin{abstract}
Abstrak
Penelitian ini bertujuan untuk menganalisis ulang penggunaan media pembelajaran dalam meningkatkan hasil belajar IPA SD. Metode yang digunakan dalam penelitian ini merupakan metode meta analisis. Penelitian ini diawali dengan mencari topik yang relevan guna memudahkan penulis dalam mengumpulkan data. Data tersebut diperoleh dengan cara menelusuri hurnal-jurnal online melalui google academia dengan kata kunci Media Pembelajaran, Meningkatkan Hasil Belajar, IPA,Sekolah Dasar. Dari penelusuran yang dilakukan diperoleh 12 artikel tetapi yang relevan untuk digumakam hanya 6 artikel. Data-data yang telah diperoleh diolah kembali menggunakan metode kuantitatif. Berdasarkan hasil analisis penggunaan media dalam pembelajaran terbukti dapat meningkatkan hasil belajar siswa paling rendah $43 \%$ dan yang paling tinggi $91 \%$. Penggunaan media pembelajaran sangat berpengaruh terhadap hasil belajar siswa dalam muatan pembelajaran IPA. Selain itu siswa juga mempunyai pengalaman yang berbeda dalam proses pembelajaran menggunakan media. Hal ini juga dapat meningkatkan kemampuan siswa dalam memahami materi pelajaran dengan mudah melalui penggunaan media selama proses pembelajaran.
\end{abstract}

Kata Kunci: Media Pembelajaran, Meningkatkan Hasil Belajar, IPA, Sekolah Dasar

\begin{abstract}
The purpose of this research was to re-analyze the use of instructional media in improving the learning outcomes of elementary school science. The method used in this research is meta-analysis method. This research begins by searching for relevant topics in order to facilitate writers in collecting data. The data was obtained by searching online journals through google academia with the keywords Learning Media, Improving Learning Outcomes, Science, Elementary School. From the search, 12 articles were obtained, but only 6 articles were relevant to be mummified. The data that has been obtained is reprocessed using quantitative methods. Based on the results of the analysis of the use of media in learning proven to be able to improve student learning outcomes at the lowest $43 \%$ and the highest $91 \%$. The use of instructional media is very influential on student learning outcomes in science learning content. In addition students also have different experiences in the learning process using media. It can also improve students' ability to understand subject matter easily through the use of media during the learning process. For 150-200 word, An abstranct is a brief summary of a research article, thesis, review, conference proceeding or any-depth analysis of a particular subject or disipline, and is often used to help the reader quickly ascertain the paper purposes. When used, an abstract always appears at the beginning of a manuscript or typescript, acting as the point-of-entry for any given academic paper or patent application. Absatrcting and indexing services for various academic discipline are aimed at compiling a body of literature for that particular subject. Abstract length varies by discipline and publisher requirements. Abstracts are typically sectioned logically as an overview of what appears in the paper.
\end{abstract}

Keywords: Learning Media, Improving Learning Outcomes, Natural Sciences, Primary Schools, metaanalysis.

@Edukatif: Jurnal Ilmu Pendidikan 2020

$\triangle$ Corresponding author :

Address :-

Email : -

ISSN 2656-8063 (Media Cetak)

Phone : - 


\section{PENDAHULUAN}

Media pembelajaran merupakan salah satu faktor yang berperan penting selama proses pembelajaran. Guru menggunakan media sebagai perantara dalam menyampaikan materi agar dapat dipahami oleh peserta didiknya dengan baik. Hamalik (dalam Arsyad, 2002: 15) mengemukakan bahwa pemakaian media pengajaran dalam proses belajar mengajar dapat membangkitkan keinginan dan minat yang baru, membangkitkan motivasi dan rangsangan kegiatan belajar, dan bahkan membawa pengaruh-pengaruh psikologis terhadap peserta didik. Derek Rowntree (dalam Rohani, 1997: 7-8) memaparkan media pembelajaran berfungsi membangkitkan motivasi belajar, mengulang apa yang telah dipelajari, menyediakan stimulus belajar, mengaktifkan respon peserta didik, memberikan balikan dengan segera dan menggalakkan latihan yang serasi. Jadi dapat disimpulkan bahwa media pembelajaran dapat digunakan guru sebagai perantara untuk menyampaikan materi kepada siswa sehingga siswa mudah memahami materi yang diajarkan.

Kata media berasal dari Bahasa latin medist yang secara herfiah berarti "tengah" atau "pengantar". Media pembelajaran adalah alat yang dapat digunakan oleh guru untuk menyampaikan informasi kepada peserta didik terkait dengan pembelajaran sehingga mudah dipahami. Arsyad (2013:3) mengemukakan bahwa kata media berasal dari bahasa Latin medius yang secara harfiah berarti 'tengah', 'perantara', atau 'pengantar'. Dalam bahasa Arab, media adalah perantara atau pengantar pesan dari pengirim kepada penerima pesan. Gerlache dan Ely (dalam Arsyad, 2013) mengatakan bahwa media apabila dipahami secara garis besar adalah manusia, materi, atau kejadian yang membangun kondisi yang membuat siswa mampu memperoleh pengetahuan, keterampilan, atau sikap. Menurut Anitah, dkk (2008: 6.11) media pembelajaran merupakan saluran atau jembatan dari pesanpesan pembelajaran (messages) yang disampaikan oleh sumber pesan (guru) kepada penerima pesan (siswa) dengan maksud agar pesan- pesan tersebut dapat diserap dengan cepat dan tepat sesuai dengan tujuannya. Menurut Association of Education Tecnology (dalam Sundayana, 2013) memberibatasan tentang media sebagai segala bentuk dan saluran yang digunakan untuk menyampaikan pes atau informasi. Apabila media itu membawa pesan-pesan atau informasi yang bertujuan instruksional atau mengandung maksud- maksud pengajaran maka media itu disebut media pengajaran.

Proses pembelajaran yang dilaksanakan oleh siswa diharapkan dapat mengembangkan prestasi belajar siswa tersebut, karena prestasi berkaitan dengan pencapaian aspek-aspek yang bersifat kognitif, afektif, dan psikomotor. Hal tersebut sesuai dengan pendapat Fatimah (2011: 95) mengatakan "dalam konteks pembelajaran ada beberapa tolak ukur yang dapat digunakan untuk mengetahui prestasi belajar siswa. Salah satu tolak ukur yang digunakan adalah prestasi belajar yang mengacu pada pencapaian taksonomi pendidikan yang mencangkup aspek kognitif,afektif, dan psikomotorik". Hal ini juga dipertegas oleh Sudjana dalam Fatimah (2011: 95) menyatakan bahwa pencapaian prestasi belajar atau hasil belajar siswa merujuk pada pencapaian aspekaspek yang bersifat kognitif, afektif, dan psikomotorik. Prestasi belajar yang ingin dicapai siswa pada pembelajaran IPA merupakan pengetahuan terkait IPA.

Pentingnya media dalam pembelajaran juga dibuktikan oleh sejumlah penelitian. Berdasarkan penelitian Rahayu S. (2006) yang berjudul "Pengembangan Multimedia Pembelajaran Pengetahuan Alam berbasis Komputer untuk Kelas V SD" menyatakan bahwa dengan multimedia pengetahuan alam kelas V SD efektif untuk meningkatkan prestasi belajar. Hasil analisis menunjukkan kenaikan skor posttest terhadap pretest sebesar $62,30 \%$ (rerata skor pretest 44,85 dan rerata skor posttest 72,79). Selanjutnya penelitian yang dilakukan oleh Marliyah pada tahun 2014 dengan judul "Upaya Meningkatkan Hasil Belajar IPA Melalui Penggunaan Alat Peraga Konkrit Pada Siswa Kelas IA SDN Darungan 01 Kecamatan Tanggul Kabupaten Jember". Menunjukkan bahwa terjadi peningkatan hasil belajar pada tiap siklus, pada siklus I ada 30 siswa $(75 \%)$ yang tuntas, sedangkan pada siklus II ada 38 siswa (98\%) yang tuntas. Penelitian selanjutnya dilakukan oleh Alfianti dkk dengan judul "Pengaruh Penggunaan Media Audio-visual Terhadap Hasil Belajar IPA Kelas V SD" di SD Negeri 66 Pontianak Kota. Hasil penelitian yaitu terjadi peningkatan hasil belajar pada pre-test dan post test yang memiliki selisih rata-rata yaitu 24,53. Pada pre-test memperoleh hasil rata-rata yaitu 45,60 dan saat posttest mendapatkan hasil rata-rata 70,14. F.Lino Spiani pada tahun 2015 melakukan penelitian dengan judul "Penggunaan Media Gambar untuk Meningkatkan Hasil Belajar Siswa dalam Pembelajaran IPA Kelas V" di SDN 
01 Nanga Mahap memperoleh hasil rata-rata pada siklus I sebesar 59 sedangkan pada siklus II sebesar 89. Dengan peningkatan dari siklus I dan II sebesar 28.29. Seriani Panjaitan juga melakukan penelitian terhadap "Meningkatkan Hasil Belajar IPA Melalui Media Gambar Pada Siswa Kelas 2A" di SDN 78 Pekanbaru yang mendapatkan hasil pada pra siklus nilai kemampuan hasil belajar siswa mempunyai rerata 43,08. Sedangkan pada pelaksanaan siklus I dan II terjadi peningkatan terhadap kemampuan hasil belajar siswa yaitu pada siklus I mempunyai rerata 61,79 dan pada siklus II mempunyai rerata 82,56. Hidayati, Nurul pada tahun 2012 melakukan penelitian di MI Manbaut Tholibin Kerjen Srengat Blitar dengan judul “ Penggunaan Media Visual (Gambar) untuk Meningkatkan Prestasi Siswa Kelas IV". Panelitian tersebut mendapatkan hasil pada tes awal siswa memperoleh nilai rata-rata 57,72 (sebelum tindakan), setelah siklus I menjadi 71,81, dan pada siklus II 82,72. Berdasarkan hasil penelitian, maka dapat disimpulkan bahwa penggunaan media visual (gambar) dalam pembelajaran IPA bisa meningkatkan prestasi belajar siswa kelas IV MI Manbaut Tholibin

Berdasarkan beberapa hasil penelitian di atas dapat disimpulkan bahwa penggunaan media dapat meningkatkan hasil belajar siswa, khususnya pada mata pelajaran IPA. Hal ini dikarenakan penggunaan media akan melibatkan siswa secara kreativ dalam proses pembelajaran untuk mengembangkan kemampuan berpikirnya sehingga terjadi peningkatan hasil belajar pada siswa.

Penulis ingin mendalami lebih lanjut dari hasil-hasil penelitian selama ini yang menunjukkan peran media sangat penting dalam pembelajaran guna meningkatkan hasil belajar IPA di SD. Guru dapat menggunakan media pembelajaran untuk meningkatkan hasil belajar peserta didik. Melalui penggunaan media pembelajaran peserta didik benar-benar terlibat langsung dan aktiv dalam pembelajaran. Proses tersebut dapat membangkitkan motivasi peserta didik untuk belajar sehingga peserta didik mau berusaha lebih ketika menemui berbagai masalah dalam proses pembelajaran. Hal ini dapat meningkatkan hasil belajar peserta didik.

Berdasarkan permasalahan-permasalahan yang berkaitan dengan hasil belajar siswa yang kurang maksimal di sekolah dasar, maka fokus penelitian ini adalah untuk menganalisis kembali apakah penggunaan media pembelajaran dapat meningkatkan hasil belajar siswa dalam muatan pembelajaran IPA? Sistematika penulisan dalam artikel ini yaitu pendahuluan, metode penelitian, hasil dan pembahasan, simpulan, saran.

\section{METODE PENELITIAN}

Penelitian ini menggunkan metode meta analisis terhadap hasil penelitian yang sudah ada sebelumnya. Merriyana (2006) Secara sederhana, meta analisis dapat diartikan sebagai analisis atas analisis. Sebagai penelitian, meta analisis merupakan kajian atas sejumlah hasil penelitian dalam masalah yang sejenis. Meta analisis merupakan salah satu cara membuat rangkuman hasil penelitian secara kuantitatif. Pengumpulan data dalam penelitian ini dilakukan dengan cara mencari jurnal pada media elektronik. Pencarian jurnal dilakukan melalui Google Academia dengan menggunakan kata kunci Media Pembelajaran, Meningkatkan Hasil Belajar, IPA,Sekolah Dasar. Dari hasil penelusuran yang diperoleh, penulis memilih 6 hasil penelitian dalam bidang studi IPA SD untuk dikaji lebih lanjut. Semua naskah yang dikaji penulis merupakan hasil dari PTK sehingga memiliki data nilai sebelum dan sesudah tindakan. Penulis melakukan kajian dengan menggunakan metode pembandingan untuk mengetahui dampak penggunaan media pembelajaran berbasis selisih skor hasil belajar siswa sebelum dan sesudah tindakan.

\section{HASIL DAN PEMBAHASAN PENELITIAN}

Setelah dilakukan penelusuran terkait Pentingnya Media dalam Pembelajaran IPA guna meningkatkan hasil belajar peserta didik maka diperoleh 12 artikel yang terkait. Dari 12 artikel yang telah diperoleh sebelumnya maka dipilih 6 diantaranya atas dasar kriteria yang sudah ditentukan. 6 artikel tersebut digunakan karena terdapat data-data yang lengkap sesuai dengan kriteria yang dibutuhkan penulis untuk dikaji. 6 artikel tersebut ditulis oleh: Muhammad Chusnul Al-Fasyi (2015) Pengaruh Penggunaan Media Video Terhadap Hasil Belajar IPA Siswa Kelas IV, F. Lino Spiani (2015) Penggunaan Media Gambar untuk Meningkatkan Hasil Belajar Siswa dalam Pembelajaran IPA Kelas V, Vinny Alfianti (2015) Pengaruh Penggunaan Media Audio-visual Terhadap Hasil Belajar IPA Kelas V SD, Seriani Panjaitan (2017) Meningkatkan Hasil Belajar IPA Melalui Media Gambar Pada Siswa Kelas 2A, Hidayati Nurul (2012) Penggunaan Media Visual (Gambar) untuk Meningkatkan Prestasi Siswa Kelas IV, dan Rahayu S. (2016) Pengembangan 
Multimedia Pembelajaran Pengetahuan Alam berbasis Komputer untuk Kelas V SD.

Berdasarkan hasil pencarian yang dilakukan menggunakan Google Academia terseleksi sepersi di atas, maka hasil analisis terkait Pentingnya Media dalam Pembelajaran Guna Meningkatkan Hasil Belajar IPA dapat diperiksa pada tabel berikut.

Tabel 1. Peningkatan Hasil Belajar IPA

\begin{tabular}{|c|c|c|c|c|c|c|}
\hline \multirow[t]{2}{*}{ No } & \multirow[t]{2}{*}{ Topik Penelitian } & \multirow[t]{2}{*}{ Peneliti } & \multicolumn{4}{|c|}{ Peningkatan Hasil Belajar } \\
\hline & & & Sebelum & Sesudah & Gain & Gain\% \\
\hline 1. & $\begin{array}{l}\text { Pengembangan Multimedia } \\
\text { Pembelajaran Pengetahuan Alam } \\
\text { berbasis Komputer untuk Kelas V } \\
\text { SD }\end{array}$ & Rahayu S & 44,85 & 72,79 & 27,94 & 62 \\
\hline 2. & $\begin{array}{l}\text { Pengaruh Penggunaan Media } \\
\text { Audio-visual Terhadap Hasil } \\
\text { Belajar IPA Kelas V SD }\end{array}$ & Vinny Alfianti & 45,60 & 70,14 & 24,53 & 53 \\
\hline 3. & $\begin{array}{l}\text { Penggunaan Media Gambar untuk } \\
\text { Meningkatkan Hasil Belajar } \\
\text { Siswa dalam Pembelajaran IPA } \\
\text { Kelas V }\end{array}$ & F. Lino Spiani & 59 & 89 & 30 & 50 \\
\hline 4. & $\begin{array}{l}\text { Meningkatkan Hasil Belajar IPA } \\
\text { Melalui Media Gambar Pada } \\
\text { Siswa Kelas 2A }\end{array}$ & $\begin{array}{c}\text { Seriani } \\
\text { Panjaitan }\end{array}$ & 43,08 & 82,56 & 39,48 & 91 \\
\hline 5. & $\begin{array}{l}\text { Penggunaan Media Visual } \\
\text { (Gambar) untuk Meningkatkan } \\
\text { Prestasi Siswa Kelas IV. }\end{array}$ & Hidayati Nurul & 57,72 & 82,72 & 25 & 43 \\
\hline 6. & $\begin{array}{l}\text { Pengaruh Penggunaan Media } \\
\text { Video Terhadap Hasil Belajar } \\
\text { IPA Siswa Kelas IV }\end{array}$ & $\begin{array}{l}\text { Muhammad } \\
\text { Chusnul Al } \\
\text { Fasyi }\end{array}$ & 50 & 82,36 & 32,36 & 64 \\
\hline & Rata-rata Pembelajaran Menggunak & Media & 50.04 & 79.92 & 29.88 & 60.5 \\
\hline
\end{tabular}

Dari tinjauan terhadap hasil penelitian, dapat dilihat bahwa dengan penggunaan media pembelajaran pada hasil belajar IPA SD dapat memberikan dampak positif. Dari 6 sampel artikel menunjukkan besarnya pengaruh penggunaan media pembelajaran. Berdasarkan data yang terdapat pada tabel 1 ternyata penggunaan media dalam pembelajaran mampu meningkatkan hasil belajar, mulai dari yang terendah $43 \%$ sampai yang tertinggi $91 \%$. Penggunaan media dalam pembelajaran menjadi solusi efektif yang dapat digunakan guru untuk meningkatkan hasil belajar siswa. Hal ini dikatakan efektif karena dapat menjadikan proses belajar mengajar menjadi menyenangkan dan tidak monoton sehingga menarik perharian siswa dalam mengikuti pembelajaran.

Hal tersebut sesuai dengan pendapat Derek Rowntree (dalam Rohani, 1997: 7-8) bahwa fungsi media pembelajaran yaitu untuk membangkitkan motivasi belajar siswa, mengulang apa yang telah dipelajari, menyediakan stimulus belajar, mengaktifkan respon siswa, memberikan balikan dengan segera dan menggalakkan latihan yang serasi. Media pembelajaran menjadi perantara guru untuk menyampaikan materi dengan cara yang berbeda dan menarik sehingga siswa memiliki motivasi yang lebih untuk belajar. Dengan demikian dapat dikatakan bahwa media pembelajaran dapat membuat siswa lebih mudah memahami materi sehingga meningkatkan hasil belajar siswa. Media pembelajaran juga dapat meningkatkan daya serap otak terhadap materi dan meningkatkan daya ingat. Apabila terjadi peningkatan terhadap daya serap dan daya ingat maka akan menigkat pula prestasi belajar siswa. Hal ini sesuai dengan pendapat para peneliti di atas. Selain itu Daryanto (2010:87) juga sependapat dengan hal tersebut. Daryanto mengatakan bahwa siswa dapat menyerap dan meningat mater dengan optimal, karena daya serap dan daya ingat siswa akan meningkat secara signifikan. 


\section{KESIMPULAN}

Berdasarkan hasil penelitian guru yang menggunakan media saat pembelajaran dapat mempermudah siswa dalam memahamu materi pelajaran sehingga memperoleh hasil belajar yang memuaskan. Dengan hasil belajar yang memuaskan maka tujuan pembelajaran dapat tercapai dengan maksimal. Selain itu, penggunaan media pembelajaran menjadikan siswa tidak terpaku pada guru yang menyajikan materi. Sesuai dengan kurikulum 2013 bahwa guru tidak menjadi sumber satu-satunya pada saat proses pembelajaran.

\section{DAFTAR PUSTAKA}

Al Fasyi, Chusnul. (2015). Pengaruh Penggunaan Media Video Terhadap Hasil Belajar IPA Siswa Kelas IV SD Negeri Ngoto Bantul Yogyakarta. Jurnal Pendidikan Guru Sekolah Dasar.

Alfianti, Vinny. (2015). Pengaruh Penggunaan Media Audio-Visual Terhadap Terhadap Hasil Belajar IPA Kelas V SD. FKIP UNTAN Pontianak.

Fanny, dkk. (2015). Pengaruh Pemanfaatan Media Pembelajaran Terhadap Hasil Belajar Siswa Kelas V SDN Pelem 2 Kecamatan Pare Kabupaten Kediri Tahun Pelajaran 2014/2015. Jurnal Artikel Ilmiah Mahasiswa.

Hidayati, Nurul. (2012). Penggunaan Media Visual (Gambar) untuk Meningjatkan Prestasi Belajar IPA Siswa Kelas IV MI Manbaut Tholibin Kerjen Srengat Blitar. FKIP Universitas Lampung. Bandar Lampung.

Kurniasari, Adesi. (2017). Pengaruh Penggunaan Media Gambar Tempel Terhadap Hasil
Belajar Siswa Tema 5 dalam Muatan Pembelajaran IPA Kelas V SDN Kutorejo 1 Kertosono. Jurnal PGSD vol 5.

Miftah. (2013). Fungsi dan Peran Media Pembelajaran Sebagai Upaya Paeningkatan Kemampuan Belajar Siswa. Jurnal Kwangsan vol 1.

Panjaitan, Seriani. (2017). Meningkatkan Hasil Belajar IPA Melalui Media Gambar pada Siswa Kelas IIA SDN 78 Pekanbaru. Jurnal Primary Program Studi PGSD Universitas Riau.

Purwanti, Lilis. (2009). Peningkatan Aktivitas Pembelajaran IPA dengan Benda Konkret pada Siswa Kelas II SDN 01 Kaling Tasikmadu Karanganyar. Skripsi dipublikasikan. Universitas Sebelas Maret Surakarta.

Spiani, Lino. (2015). Penggunaan Media Gambar untuk Meningkatkan Hasil Belajar Siswa dalam Pembelajaran IPA Kelas V. Skripsi dipublikasikan. FKIP Universitas Tanjungpura Pontianak.

S, Rahayu. (2006). Pengembanhan Multimedia Pembelajaran Pengetahuan Alam Berbasis Komputer untuk Kelas IV SD. Google Scholar.

Wahyunita, Ninuk dan Samawi Ahmad. (2014). Pengaruh Penggunaan Media Animasi Terhadap Hasil Belajar IPA Siswa Slow Learner. Jurnal P3LB vol 1.

Wijayanto, Erwin. (2017). Pengaruh Penggunaan Media Game Edukasi Terhadap Hasil Belajar IPA Siswa Kelas IV SDN Kajartengguli Prambon Sidoarjo. Jurnal PGSD vol 5. 